\title{
Role of Dorsomedial Hypothalamic Neuropeptide Y in Modulating Food Intake and Energy Balance
}

\author{
Liang Yang, ${ }^{\star}$ Karen A. Scott, ${ }^{\star}$ Jayson Hyun, Kellie L. Tamashiro, Nancy Tray, Timothy H. Moran, and Sheng Bi \\ Department of Psychiatry and Behavioral Sciences, Johns Hopkins University School of Medicine, Baltimore, Maryland 21205
}

Previous studies have suggested that neuropeptide Y (NPY) in the dorsomedial hypothalamus (DMH) serves as an important signaling peptide in the regulation of energy balance. To elucidate such actions, we used the adenoassociated virus (AAV) system to alter Npy gene expression in the DMH and examined the effects of these alterations on food intake and energy balance as well as explored its downstream signaling pathway. We found that AAV-mediated overexpression of NPY in the DMH of lean rats increased food intake and body weight, and exacerbated high-fat diet-induced obesity. Knockdown of NPY expression in the DMH via AAV-mediated RNA interference ameliorated the hyperphagia, obesity, and diabetes of Otsuka Long-Evans Tokushima Fatty (OLETF) rats. NPY knockdown in the DMH produced a nocturnal and meal size-specific feeding effect. Moreover, we found that knockdown of DMH NPY expression in intact rats reduced NPY content in the nucleus of the solitary tract (NTS) and the dorsal motor nucleus of the vagus and affected within-meal satiation. DMH NPY knockdown increased the feeding inhibitory and NTS c-Fos responses to peripheral administration of cholecystokinin. Together, these results indicate that DMH NPY plays an important role in modulating food intake and energy balance and its dysregulation causes disordered energy balance leading to obesity.

Key words: hypothalamus; nucleus of the solitary tract; feeding; obesity; adenoassociated virus; RNAi

\section{Introduction}

Hypothalamic peptide signaling systems play key roles in the control of energy balance. Neuropeptide Y (NPY) is a potent hypothalamic orexigenic peptide. Central administration of NPY causes robust increases in food intake and body weight and, with chronic administration, can eventually produce obesity (Clark et al., 1984; Levine and Morley, 1984; Stanley and Leibowitz, 1984; Stanley et al., 1986; Zarjevski et al., 1993). Although NPY immunoreactivity is widely distributed throughout the hypothalamus (Chronwall et al., 1985; Gray and Morley, 1986), in situ hybridization histochemistry has revealed that $N p y$-expressing neurons are primarily localized in the arcuate nucleus (ARC) and the dorsomedial hypothalamus (DMH) (White and Kershaw, 1990; Bi et al., 2003). The actions of ARC NPY in the controls of food intake and body weight have been well studied. ARC NPY serves as a neural signal that integrates hormonal (such as leptin and ghrelin) and nutrient signals to modulate food intake and body weight (Elmquist et al., 1999; Nakazato et al., 2001; Spiegelman and Flier, 2001; Schwartz and Porte, 2005). NPY neurons in the ARC project to the paraventricular nucleus (PVN) and lateral hypothalamus ( $\mathrm{LH}$ ) and act on local neurons to affect food intake and body weight (Elmquist et al., 1999). In support of this view,

Received Sept. 12, 2008; revised 0ct. 13, 2008; accepted Nov. 17, 2008.

This work was supported by National Institute of Diabetes and Digestive and Kidney Diseases Grants DK074269 (S.B.) and DK057609 (T.H.M.).

*L.Y. and K.A.S. contributed equally to this work.

Correspondence should be addressed to Sheng Bi, Department of Psychiatry and Behavioral Sciences, Johns Hopkins University School of Medicine, 720 Rutland Avenue, Ross 618, Baltimore, MD 21205. E-mail: sbi@jhmi.edu.

K. A. Scott's present address: Department of Psychiatry, University of Cincinnati, Cincinnati, $\mathrm{OH} 45237$.

D0I:10.1523/JNEUROSCI.4379-08.2009

Copyright $\odot 2009$ Society for Neuroscience $\quad$ 0270-6474/09/290179-12\$15.00/0 adenoassociated virus (AAV)-mediated expression of antisense Npy cRNA in the ARC of adult rats decreases ARC NPY expression and results in decreases in food intake and body weight (Gardiner et al., 2005). Moreover, AAV-mediated ectopic overexpression of NPY within the PVN or the LH results in increases in food intake and body weight with different durations and mechanisms of action (Tiesjema et al., 2007).

The functions of DMH NPY in the regulation of energy balance are less clear. We and other investigators have reported that Npy gene expression is induced or significantly elevated in the DMH of rats in response to lactation (Smith, 1993), chronic food restriction (Bi et al., 2003), and increased physical activity (Kawaguchi et al., 2005). Induction or overexpression of Npy in the DMH has also been found in several rodent models of obesity including the lethal agouti yellow Ay (Kesterson et al., 1997), melanocortin 4 receptor knock-out (Kesterson et al., 1997), tubby (Guan et al., 1998a), diet-induced obese (Guan et al., 1998b), and brown adipose tissue-deficient obese mice (Tritos et al., 1998), as well as the Otsuka Long-Evans Tokushima Fatty (OLETF) rats (Bi et al., 2001). Despite these findings, existing data to date are correlational and the role of DMH NPY in mediating such effects has yet to be determined.

Here, we sought to ascertain the role of DMH NPY in energy balance by using the AAV system to alter DMH NPY signaling via either increased or decreased Npy gene expression in the DMH. We demonstrate that alterations in DMH NPY signaling have bidirectional effects on food intake and body weight. Moreover, we identify an action of DMH NPY projections to the brainstem in modulating within-meal satiation signaling that may underlie the overall actions of DMH NPY in feeding control. 


\section{Materials and Methods}

Cell lines. AAV-293 cells were purchased from Stratagene and used for viral preparation. Cells were cultured in DMEM growth medium (containing $4.5 \mathrm{~g} / \mathrm{L}$ glucose, $110 \mathrm{mg} / \mathrm{L}$ sodium pyruvate, and $4 \mathrm{~mm} \mathrm{~L}-\mathrm{glu}-$ tamine; Invitrogen) supplemented with $10 \%(\mathrm{v} / \mathrm{v})$ heat-inactivated fetal bovine serum.

Animals. Male Sprague Dawley rats were purchased from Charles River Laboratories. Male OLETF rats and age-matched male lean LongEvans Tokushima Otsuka (LETO) rats were obtained as a generous gift from the Tokushima Research Institute, Otsuka Pharmaceuticals (Tokushima, Japan). Rats were individually housed in hanging wire mesh cages and maintained on a $12 \mathrm{~h}$ light/dark cycle (lights on at 6:00 A.M.) in a temperature-controlled colony room $\left(22-23^{\circ} \mathrm{C}\right)$ with ad libitum access to tap water and standard laboratory rodent chow, except where noted. All procedures were approved by the Institutional Animal Care and Use Committee at The Johns Hopkins University.

$A A V$-mediated NPY expression vector. The AAV Helper-Free System (Stratagene) was used for viral preparation. The full length of rat Npy cDNA was first cloned into the pAAV-IRES-hrGFP vector to make a recombinant NPY expression plasmid (pAAVNPY), so that the plasmid contains the Npy gene driven by the cytomegalovirus (CMV) promoter and the marker gene of humanized Renilla green fluorescent protein (hrGFP) translationally controlled by the internal ribosome entry site (IRES), flanked by AAV2 inverted terminal repeats (ITRs) (see Fig. $1 A$ ). For viral packaging, three plasmids of pAAVNPY, pHelper (carrying adenovirus-derived genes), and pAAV-RC (carrying AAV-2 replication and capsid genes) were cotransfected into the AAV-293 cells according to the manufacturer's protocol (Stratagene). The vector pAAV-hrGFP was used for packaging the control viral vector AAVGFP. Three days after transfection, cells were harvested, and the recombinant viral vector AAVNPY (or AAVGFP) was purified using the AAV purification kit (Virapur) and concentrated using Centricon YM-100 (Millipore) according to the manufacturers' protocols. Viral titers were determined using quantitative PCR and $\sim 1 \times 10^{9}$ particles/site were used for each viral injection.

NPY overexpression in the DMH of Sprague Dawley rats. Twelve 10week-old male Sprague Dawley rats weighing 300-325 g were randomly divided into the two groups. One group of six rats received bilateral DMH injections of AAVNPY, and the other group of six rats received bilateral DMH injections of AAVGFP. Rats were anesthetized with an intraperitoneal injection of a mixture of ketamine $(100 \mathrm{mg} / \mathrm{kg})$ and $x y-$ lazine $(20 \mathrm{mg} / \mathrm{kg})$ and placed in a stereotaxic apparatus. A volume of 0.3 $\mu \mathrm{l} /$ site $\left(\sim 1 \times 10^{9}\right.$ particles/site) of recombinant AAV vectors were bilaterally injected into the DMH with the following coordinates: $3.1 \mathrm{~mm}$ caudal to bregma, $0.4 \mathrm{~mm}$ lateral to midline, and $8.6 \mathrm{~mm}$ ventral to skull surface. Each DMH injection was made with a Hamilton syringe via stepper-motorized nanoliter injection pump (Stoelting) at a rate of 0.05 $\mu \mathrm{l} / \mathrm{min}$ for $6 \mathrm{~min}$ and the injection remained in place for additional $5 \mathrm{~min}$ before removal. After viral injection, rats continued to have ad libitum access to standard rodent chow (a regular chow diet: 15.8\% fat, $65.6 \%$ carbohydrate, and $18.6 \%$ protein in $\mathrm{kcal} \%$; $3.37 \mathrm{kcal} / \mathrm{g}$; Prolab RMH 1000; PMI Nutrition International) for 5 weeks. Five weeks later, rats were switched to ad libitum access to a high-fat diet (60\% fat, $20 \%$ carbohydrate, and 20\% protein in kcal\%; $5.2 \mathrm{kcal} / \mathrm{g}$; D12492; Research Diets) for an additional 6 weeks. Body weights were measured daily and food intake was recorded weekly. Eleven weeks after viral injection, rats were killed between 9:00 A.M. and 11:00 A.M., and brains were removed and rapidly frozen for subsequent examination of hrGFP expression and hypothalamic NPY expression.

$A A V$-mediated RNA interference vector. Four short hairpin RNAs (shRNAs) directed to different target sites of Npy mRNA (shNPY1, base pairs 81-101; shNPY2, base pairs 240-60; shNPY3, base pairs 335-55; shNPY4, base pairs 270-90) (see Fig. 2A) based on the rat Npy mRNA sequence (GenBank NM_012614) were made using the pSilencer 1.0-U6 siRNA expression vector (Ambion). A scrambled shRNA (5'AATGTGTCGGGGTAAGCAAAC- $3^{\prime}$ ) was also made and served as a control (shCTL). For in vitro screen, the shRNA expression plasmid was cotransfected into the AAV 293 cells with the Npy expression plasmid
pAAVNPY at a ratio of 8:1 using Lipofectamine 2000. Seventy-two hours after transfection, total RNA was extracted for determination of $N p y$ mRNA levels using quantitative real-time RT-PCR. After identification of shNPY2, the insert of DNA containing mouse U6 promoter and shRNA sequence cut from the shNPY2 or control shCTL plasmid was cloned into the pAAV-hrGFP vector (Stratagene). Thus, the two cassettes of CMV promoter driven hrGFP marker and mouse U6 promoter driven shRNA (shNPY or shCTL) were made in the pAAV-hrGFP plasmids (pAAVshNPY or pAAVshCTL), flanked by AAV2 ITR (see Fig. 3A). Subsequent viral preparation (AAVshNPY or AAVshCTL) was conducted as described above.

Injection of $A A V$ shNPY into the ARC. Ten male Sprague Dawley rats weighing 275-300 g served as subjects. Rats were randomly divided into the two groups ( $n=5$ rats per group): one group receiving AAVshNPY and the other group receiving AAVshCTL. Rats were anesthetized with an intraperitoneal injection of a mixture of ketamine $(100 \mathrm{mg} / \mathrm{kg})$ and xylazine $(20 \mathrm{mg} / \mathrm{kg})$ and placed in a stereotaxic apparatus. A volume of $0.3 \mu \mathrm{l} /$ site $\left(\sim 1 \times 10^{9}\right.$ particles/site $)$ of recombinant AAV vectors were bilaterally injected into the ARC with coordinates: $3.1 \mathrm{~mm}$ caudal to bregma, $0.4 \mathrm{~mm}$ lateral to midline, and $10 \mathrm{~mm}$ ventral to skull surface. Each ARC injection was made as described above. Rats were maintained with ad libitum access to standard rodent chow and tap water after viral injection. On day 14 after viral injection, we tested the feeding response to food deprivation in the rats. Before food deprivation, $24 \mathrm{~h}$ food intake was recorded as a baseline. All rats were food deprived for $24 \mathrm{~h}$ but continued ad libitum access to water. After $24 \mathrm{~h}$ of food deprivation, all rats were refed with standard chow, and $24 \mathrm{~h}$ food intake was measured after refeeding. Rats were then allowed to recover for $6 \mathrm{~d}$ with ad libitum access to food. On day 21 after viral injection, all rats were killed between 9:00 A.M. and 10:00 A.M., and brains were removed rapidly and frozen for subsequent determinations of mRNA expression for Npy and Agrp using our standard in situ hybridization technique (Bi et al., 2003).

Injection of AAVshNPY into the DMH of OLETF rats. At 4 weeks of age, 12 male OLETF rats weighing 71-99 g and six male age-matched LETO rats weighing 81-95 g received viral injections. Rats were randomly divided into the three groups: one group of six OLETF rats received bilaterally DMH injections of AAVshNPY (OLETF-AAVshNPY), the second group of six OLETF rats received bilaterally DMH injections of AAVshCTL (OLETF-AAVshCTL), and the third group of six LETO rats received bilaterally DMH injections of AAVshCTL (LETO-AAVshCTL). DMH viral injections were made as described above with the following coordinates: $2.1 \mathrm{~mm}$ caudal to bregma, $0.4 \mathrm{~mm}$ lateral to midline, and $7.6 \mathrm{~mm}$ ventral to skull surface. After viral injection, rats were maintained with ad libitum access to standard rodent chow and tap water. Body weights were measured daily and food intake was recorded weekly. Oral glucose tolerance test (OGTT) was conducted in rats at 18 weeks of age. At 24 weeks of age, rats were killed between 9:00 A.M. and 11:00 A.M. The left side of epidydimal and inguinal subcutaneous white adipose tissue as well as interscapular brown adipose tissue were harvested and weighed. Trunk blood was taken for evaluating levels of blood glucose and plasma leptin and triglycerides. Blood glucose levels were determined with a FreeStyle glucometer (TheraSense), plasma leptin concentration was determined by a rat leptin radioimmunoassay kit (Linco Research) and plasma triglyceride concentration was determined by a Triglyceride M kit (Wako Chemical). Brains were removed and rapidly frozen for subsequent determinations of hrGFP expression and hypothalamic NPY expression.

Analysis of meal patterns. An additional 12 male OLETF and six agematched male LETO rats were used for analyses of meal patterns. Bilateral DMH viral injections were made as described above. Six OLETF rats received AAVshNPY injections, the other six OLETF rats received AAVshCTL injections, and six LETO rats received AAVshCTL injections. Two weeks after viral injection, rats were transferred to individual test cages containing computerized feeding devices (MED Associates), which delivered $45 \mathrm{mg}$ chow pellets. Rats had ad libitum access to pellets and water. Individual pellets were delivered in response to the removal of the previous pellet. The delivery of each pellet was monitored, time stamped, and stored $24 \mathrm{~h} / \mathrm{d}$ in a computer. Rats were adapted to the testing apparatus for $7 \mathrm{~d}$. After adaptation, data for $24 \mathrm{~h}$ food intake were collected and meal patterns were analyzed using the software (Tongue Twister, 
A

\section{ITR CMV IRPY IRES hrGFP-}

B
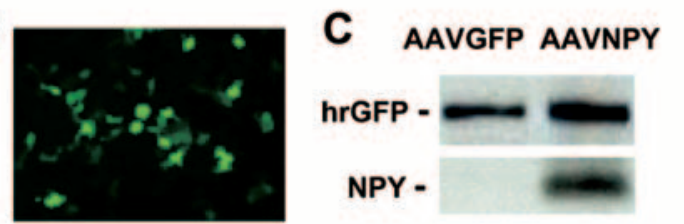

E AAVGFP

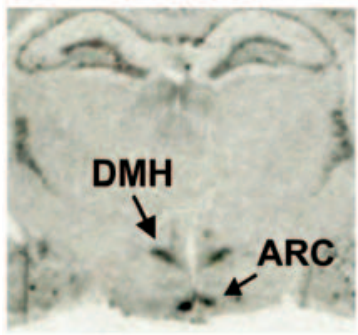

$\mathbf{F}$
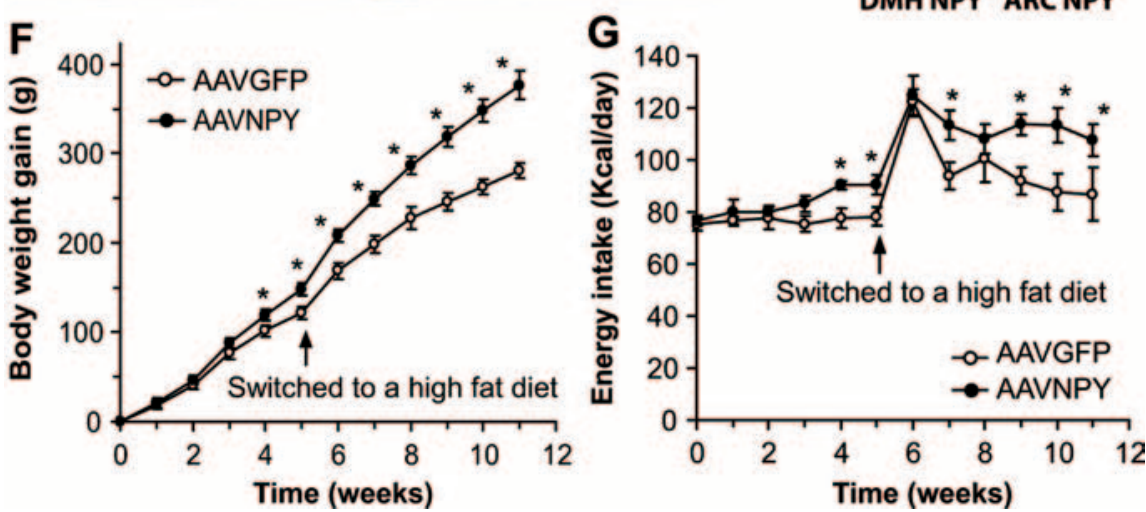

Figure 1. Effects of AAV-mediated overexpression of NPY in the DMH on food intake and body weight in lean rats. $A$, Construct of AAV-mediated Npy expression vector (AAVNPY) containing the Npy gene driven by the CMV promoter and the expression marker of hrGFP translationally controlled by the IRES, flanked by AAV2 ITRs. $\boldsymbol{B}$, Representative micrograph shows hrGFP expression in AAVNPY-infected AAV293 cells as examined under fluorescence microscopy. C, Western blot detected NPY product in AAVNPY-infected AAV293 cells. AAVGFP, Control vector lacking Npy gene. D, Representative micrograph shows hrGFP expression

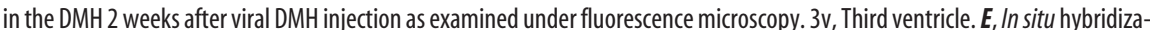
tion with ${ }^{35}$ S-labeled antisense riboprobe of Npy determined AAV-mediated Npy overexpression in the DMH at 11 weeks after viral DMH injection. Values are mean \pm SEM. $n=6$ rats per group. ${ }^{*} p<0.05$ compared with AAVGFP rats. $F$, Mean \pm SEM body weight gain in AAVNPY- and AAVGFP-injected rats. $n=6$ rats per group. ${ }^{*} p<0.05$ compared with AAVGFP rats. G, Mean \pm SEM daily food intake in AAVNPY and AAVGFP rats. $n=6$ rats per group. ${ }^{*} p<0.05$ compared with AAVGFP rats.

version 1.42; Dr. T. A. Houpt, Florida State University, Tallahassee, FL). A meal was defined as the acquisition of at least five pellets preceded and followed by at least $20 \mathrm{~min}$ of no feeding. Meal size was defined as the number of pellets delivered during a meal (Moran et al., 1998). Five weeks after viral injection, rats were killed, and brains were removed and rapidly frozen for subsequent determination of hypothalamic gene expression as above.

Oral glucose tolerance test. After a $16 \mathrm{~h}$ overnight fast, rats were administered with glucose at a dose of $2 \mathrm{~g} / \mathrm{kg}$ by gavage. Tail blood was sampled before and 15, 30, 45, 60, and 120 min after giving glucose for the measurements of blood glucose and plasma insulin levels. Blood glucose levels were determined with a FreeStyle glucometer (TheraSense). Plasma insulin concentrations were determined by a rat insulin radioimmunoassay kit (Linco Research).

Quantitative in situ hybridization. Radioactive in situ hybridization was conducted as previously described (Bi et al., 2003). Briefly, ${ }^{35} \mathrm{~S}$ labeled antisense riboprobe of $N p y$ was transcribed from rat Npy precur- sor cDNA by using the in vitro transcription system (s) (Promega). Sections ranging from 3.0 to $3.5 \mathrm{~mm}$ posterior to bregma (Paxinos and Watson, 2005) were selected, anatomically matched among animals, and used for determination of Npy mRNA levels in the DMH and the ARC. Sections were treated with acetic anhydride and incubated in our standard hybridization buffer at $55^{\circ} \mathrm{C}$ overnight. After hybridization, sections were washed three times with $2 \times$ SSC, treated with $20 \mu \mathrm{g} / \mathrm{ml}$ RNase A (SigmaAldrich) at $37^{\circ} \mathrm{C}$ for $30 \mathrm{~min}$, and then rinsed in $2 \times$ SSC twice at $55^{\circ} \mathrm{C}$, and washed twice in $0.1 \times \mathrm{SSC}$ at $55^{\circ} \mathrm{C}$ for $15 \mathrm{~min}$. Slides were dehydrated in gradient ethanol, air-dried, and exposed with BMR-2 film (Eastman Kodak) for 1-3 d. For emulsion autoradiography, slides were dipped in Amersham LM1 emulsion (GE Healthcare Life Sciences), exposed at $4^{\circ} \mathrm{C}$ for 10-14 d, and developed in Kodak D-19 developer and Kodak fixer (Kodak) according to the manufacturer's protocols.

Quantitative analysis of the in situ hybridization data were done with NIH Scion image software as previously described (Bi et al., 2003). Levels of Npy mRNA were determined by a mean of the product of hybridization area $X$ density (background density was subtracted) in each animal. Data from each group were normalized to the control group as $100 \%$.

Dual fluorescent in situ hybridization and immunohistochemistry. Fluorescence in situ hybridization was first conducted for detecting Npy mRNA as previously described (Bi et al., 2003). Briefly, nonradioactive riboprobe of $N p y$ was labeled with digoxigenin (DIG)-11-UTP by the in vitro transcription systems (Promega), and applied on brain sections by use of our standard in situ hybridization procedure. After hybridization and posthybridization washes, DIG-labeled Npy signals were detected by using a fluorescent antibody enhancer set for DIG Detection kit (Roche) with some modifications. Three kinds of antibodies (mouse IgG anti-DIG and anti-mouse-Ig-DIG each in a final concentration of $1 \mathrm{ng} / \mu \mathrm{l}$ from Roche and anti-DIG mouse IgG-Cy3 at a 1:1000 dilution from Jackson ImmunoResearch) were sequentially applied to brain sections, and each incubation step was followed by three washes with washing buffer according to the manufacturer's protocol. After Npy mRNA detection, fluorescent immunohistochemistry was conducted for detecting hrGFP product. Briefly, sections were incubated with rabbit antihrGFP antibody (1:1000 dilution; Stratagene) at $4^{\circ} \mathrm{C}$ overnight. After three washes, hrGFP signals were stained with Alexa Fluor 488 goat antirabbit antibody (1:350 dilution; Invitrogen) at room temperature for 60 min. After final washes, the slides were mounted with the mounting medium and coverslipped, and the sections with dual fluorescent staining of hrGFP (green) and Npy (red) were examined on a Zeiss Axio Imager (Carl Zeiss MicroImaging).

Determination of DMH NPY signaling to the brainstem. Five male Sprague Dawley rats received unilateral DMH injection of AAVshNPY. Four weeks after viral injection, rats were anesthetized with Euthasol and perfused transcardially with $\mathrm{PBS}, \mathrm{pH} 7.4$, followed by $4 \%$ paraformaldehyde in PBS. Brains were removed and placed in $25 \%$ sucrose- $4 \%$ paraformaldehyde overnight. NPY immunostaining was conducted as previously described (Bi et al., 2004). Briefly, $14 \mu \mathrm{m}$ coronal sections at the level(s) of the brainstem dorsal vagal complex (DVC) were prepared and 
incubated with anti-NPY monoclonal antibody (a gift from Dr. Eric Grouzmann, Centre Hospitalier Universitaire Vaudois, Lausanne, Switzerland). After three wishes, sections were incubated with $\mathrm{Cy} 3$-conjugated donkey anti-mouse IgG (at 1:400 dilutions; Jackson ImmunoResearch) at room temperature for $1 \mathrm{~h}$. After final washes, the slides were mounted with the mounting medium and coverslipped, and the sections with NPY (red) fluorescence were examined on a Zeiss Axio Imager (Carl Zeiss MicroImaging).

An additional 10 male Sprague Dawley rats were used for determination of NPY protein levels in the DVC of AAVshNPY-injected rats. One group of five rats received bilateral DMH injections of AAVshNPY, and the other group of five rats received bilateral DMH injections of AAVshCTL. Four weeks after viral injection, rats were killed, and the tissues at levels of the $\mathrm{DMH}$, the ARC, and the DVC were punched out, the samples from both sides of the $\mathrm{DMH}$, the ARC, and one side of the DVC were used for Npy mRNA determinations by quantitative real-time RT-PCR, and the samples from the other side of the DVC were used for NPY protein determinations by Western blot analysis.

Feeding response to peripheral administration of cholecystokinin. Twenty male Sprague Dawley rats were randomly divided into the two groups. One group of 10 rats received bilateral DMH injections of AAVshNPY, and the other group of 10 rats received bilateral DMH injections of AAVshCTL. Three weeks after viral injection, rats were transferred to individual test cages for meal pattern analysis as described above. After this analysis, rats were returned to home cages to study feeding response to peripheral administration of cholecystokinin (CCK). As previously described (Chen et al., 2007), rats were fed in a feeding schedule in which pelleted chow was removed from the cages $2 \mathrm{~h}$ before lights off and returned to the cages just before dark onset. After habituation(s), one-half of AAVshNPY and AAVshCTL rats received CCK-8 $(3.2 \mathrm{nmol} / \mathrm{kg}$, i.p.) and the other onehalf of the rats received $0.9 \%$ saline (intraperitoneally) just before lights off. Pelleted chow was returned to the cages immediately after injections. Thirty minute food intake was measured. After $2 \mathrm{~d}$ recovery, all rats were given a second injection with saline or CCK-8 (3.2 nmol/kg, i.p.) in counterbalanced order. Food intake was measured as after the first injections.

c-Fos immunohistochemistry. After feeding tests, c-Fos immunohistochemistry was conducted. Rats were randomly divided into four groups. One-half of AAVshNPY and AAVshCTL rats received CCK-8 (3.2 nmol/ $\mathrm{kg}$, i.p.) and the other one-half of the rats received $0.9 \%$ saline (intraperitoneally), but the rats were not allowed to access to chow after injection. Ninety minutes after injection, the rats were anesthetized with Euthasol and perfused transcardially with $\mathrm{PBS}, \mathrm{pH} 7.4$, followed by $4 \%$ paraformaldehyde in PBS. Brains were removed and placed in 25\% sucrose- $4 \%$ paraformaldehyde overnight. Forty micrometer coronal sections were cut on a cryostat at the level through the rostrocaudal extent of the nucleus of the solitary tract (NTS). Sections were incubated with c-Fos antibody as previously described (Chen et al., 2007). After staining, sections were mounted on gelatin-coated slides and coverslipped. Images of sections were captured by digital camera attached to Zeiss Axio Imager (Carl Zeiss MicroImaging). c-Fos-positive cells were automatically counted by the IPLab imaging system (BD Biosciences Bioimaging) by setting minimum and maximum optical density levels. Counts were made at three rostrocaudal levels of the NTS at the following distances (in millimeters) caudal to bregma (Paxinos and Watson, 2005): rostral NTS $(-13.44)$; medial NTS at the area postrema (AP) (-13.8); caudal NTS $(-14.28)$; and one level of the AP (-13.8); Data for c-Fos activation are presented as the total number of c-Fos-positive cells per section.

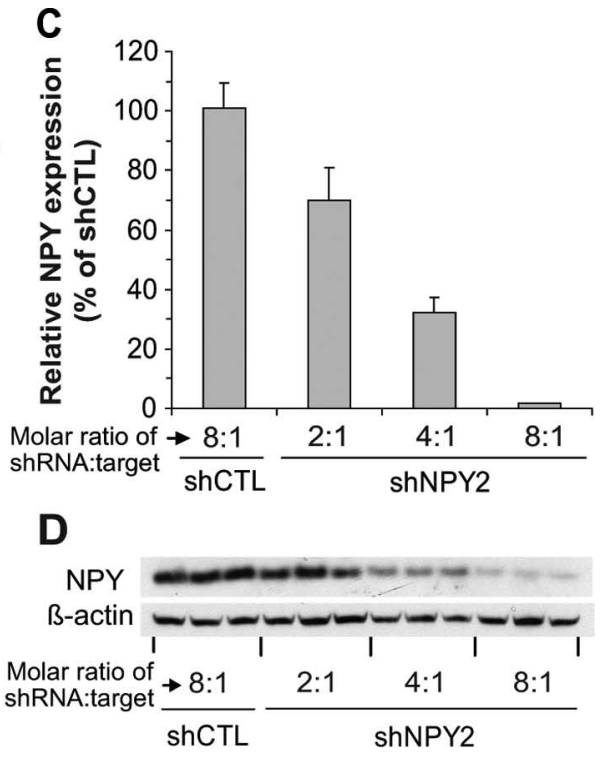

Figure 2. Screen of shRNAs for knocking down NPY expression (shNPY). $\boldsymbol{A}$, Four shRNAs directed to four different target sites of Npy mRNA (shNPY1-4) were made using the pSilencer 1.0-U6 siRNA expression vector. $\boldsymbol{B}$, In vitro screen of shNPYs by cotransRT-PCR. D, Dose-related effects of shNPY2 on NPY products in AV293 cells cotransfected with shNPY2 and NPY target plasmids (at ranges of 2:1, 4:1, and 8:1) as determined by Western blot. Error bars indicate SEM.

Quantitative real-time reverse transcription-PCR. Total RNA was extracted from each sample by using Trizol reagent (Invitrogen) according to the manufacturer's protocol. Conventional real-time reverse transcription (RT)-PCR was conducted for determinations of mRNA levels by using the iScript one-step RT-PCR kit with SYBR Green (Bio-Rad Laboratories) on iQ5 Multicolor Real-Time PCR Detection System (BioRad Laboratories). $\beta$-Actin was used as an internal control for quantification of individual mRNA. The list of primer sets was as follows: NPY, forward primer, $5^{\prime}$-agagatccagccctgagaca- $3^{\prime}$, and reverse primer, $5^{\prime}$-aacgacaacaagggaaatgg- $3^{\prime} ; \beta$-actin, forward primer, $5^{\prime}$-tgtcaccaactgggacgata- $3^{\prime}$, and reverse primer, $5^{\prime}$-ggatggctacgtacatggct-3'; CCK1 receptors, forward primer, $5^{\prime}$ gcggacggtcaccaacatcttc- $3^{\prime}$, and reverse primer, $5^{\prime}$-cggaagtgcccatgaagtaggtg$3^{\prime}$; and hrGFP, forward primer, $5^{\prime}$-ccccgaggacatcagcgactt- 3 ', and reverse primer, $5^{\prime}$-cgcggtacacgaacatctcctc- $3^{\prime}$.

Western blot. Twenty micrograms of cell lysate protein or DVC protein lysate was separated by using $12 \%$ SDS-PAGE, and transferred to a nitrocellulose membrane. The membrane was then incubated with rabbit anti-NPY antibody (1:1000 dilutions; DiaSorin), followed by horseradish peroxidase-labeled anti-rabbit antibody (1:5000 dilutions; GE Healthcare) and detected by ECL Western blotting detection reagents and analysis system (GE Healthcare).

Analyses of data. Data were analyzed using the commercial software (SigmaStat, version 3.10). Data for body weight gain and food intake were analyzed using two-way repeated-measures ANOVA, and data for $N p y$ mRNA expression were analyzed using Student's $t$ test in the experiment of AAV-mediated NPY overexpression. Data for food intake were analyzed using two-way ANOVA and data for Npy and Agrp mRNA expression in the ARC were analyzed using Student's $t$ test in the experiment of AAV-mediated RNA interference (RNAi) in the ARC of Sprague Dawley rats. Data for body weight gain, food intake, meal patterns, and levels of blood glucose and plasma insulin, leptin, and triglyceride as well as Npy mRNA expression were analyzed using one-way ANOVA in the experiment of AAV-mediated RNAi in the DMH of OLETF rats. Data for food intake and c-Fos activation in response to peripheral administration of CCK were analyzed using two-way ANOVA. All ANOVAs were followed by pairwise multiple Fisher's least 
A
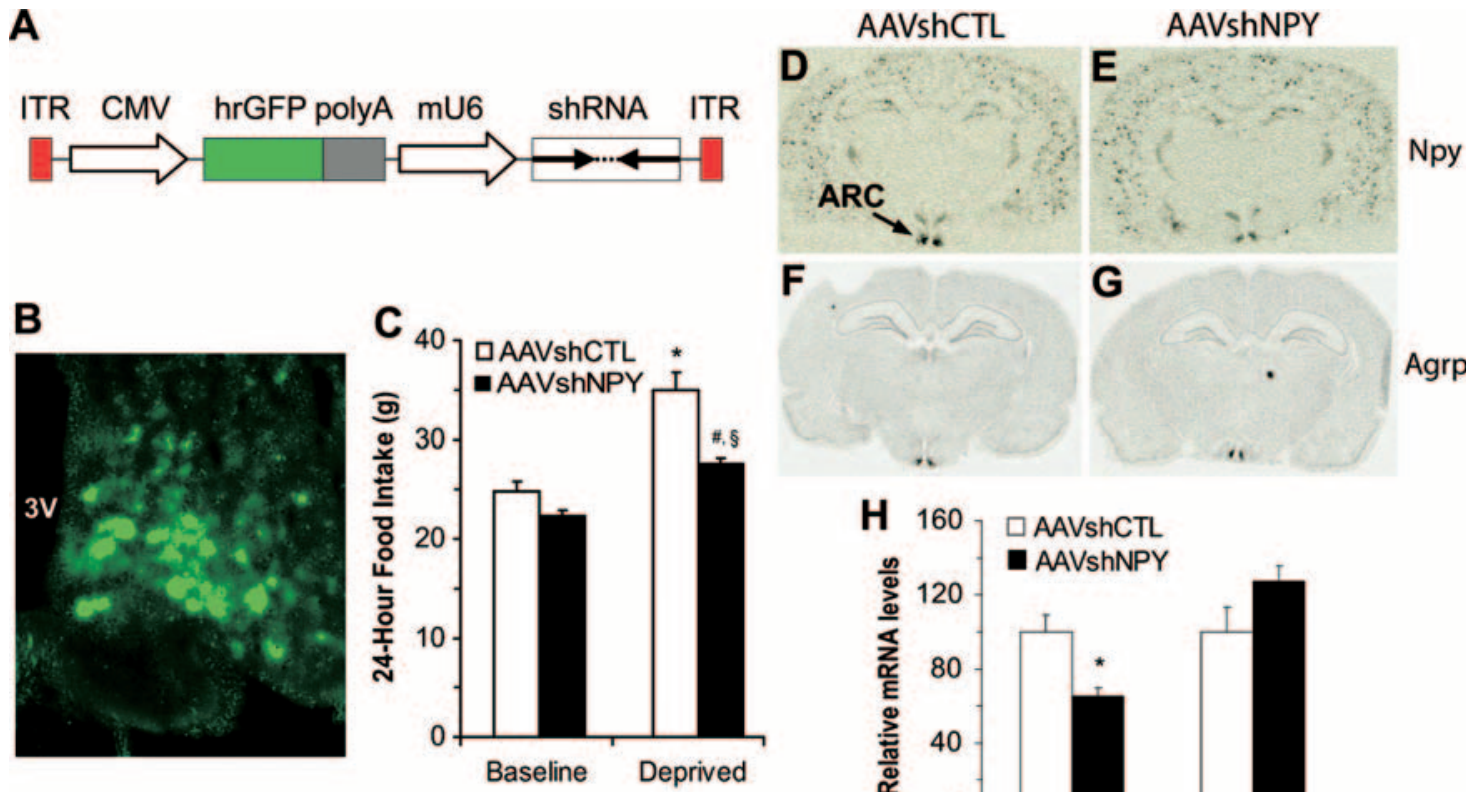

$\mathbf{F}$

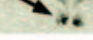

G
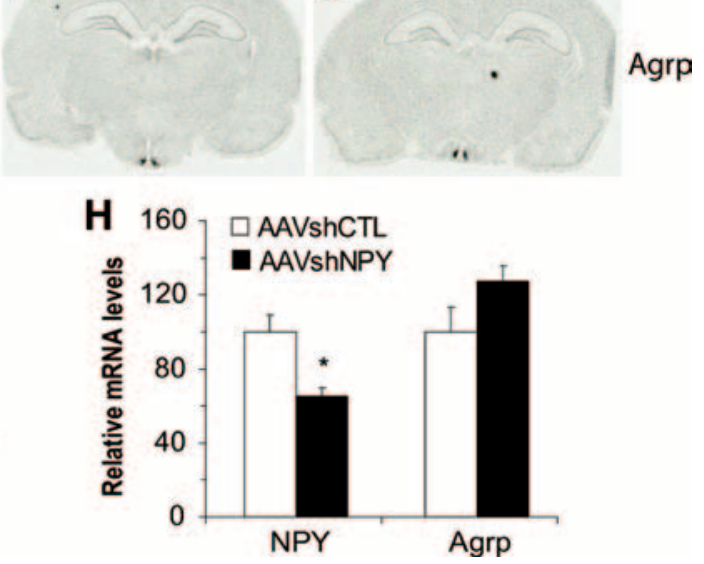

Figure 3. Bilateral injections of AAVshNPY into the ARC altered ARC NPY functions. A, Construct of AAV-mediated RNAi vector (AAVshNPY or AAVshCTL) containing CMV promoter-driven hrGFP marker and mouse U6 promoter (mU6)-driven shRNA (shNPY or shCTL). $\boldsymbol{B}$, Representative micrograph shows viral-infected neurons in the ARC as examined by hrGFP expression. $\boldsymbol{C}$, Injection of AAVshNPY into the ARC bilaterally decreased feeding response to $24 \mathrm{~h}$ food deprivation. Mean \pm SEM $24 \mathrm{~h}$ food intake was examined in the two groups of rats receiving AAVshCTL or AAVshNPY before (baseline) and after $24 \mathrm{~h}$ food deprivation (deprived). AAVshCTL, AAV-mediated shCTL; AAVshNPY, AAV-mediated shNPY. $n=5$ rats per group. ${ }^{*} p<0.05$ compared with the basal intake of AAVshCTL rats, ${ }^{\#} p<0.05$ compared with the basal intake of AAVNPY rats, and ${ }^{\S} p<0.05$ compared with the intake of AAVshCTL rats after food deprivation. $\boldsymbol{D}, \boldsymbol{E}$, In situ hybridization with ${ }^{35}$ S-labeled antisense riboprobe of Npy shows decreased Npy expression in the ARC of AAVshNPY rats $(\boldsymbol{E})$ relative to AAVshCTL rats (D). $\boldsymbol{F}, \boldsymbol{G}$, In situ hybridization with ${ }^{35}$ S-labeled antisense riboprobe of AgRP shows normal Agrp expression in the ARC in AAVshCTL rats $(\boldsymbol{F})$ and AAVshNPY rats $(\boldsymbol{G})$. $\boldsymbol{H}$, Knockdown effects of ARC AAVshNPY injection on levels of Npy but not Agrp mRNA in the ARC of AAVshNPY rats as determined by in situ hybridization. Values are means \pm SEM. $n=5$ rats per group. ${ }^{*} p<0.05$ compared with AAVshCTL rats.

significant difference comparisons. A value of $p<0.05$ was considered to be a statistically significant difference.

\section{Results}

AAV-mediated overexpression of NPY

AAV serotype 2 has widely been used as a means of brain gene delivery with features of safety, neuronal- and injection sitespecific infection, and maintaining gene expression for long periods (Okada et al., 2002; Passini et al., 2004). Using this viral vector, we generated a recombinant vector of AAV-mediated expression of NPY (AAVNPY). As shown in Figure $1 A$, the vector AAVNPY contains the Npy gene driven by the CMV promoter and the hrGFP marker gene translationally controlled by the IRES, and the vector is flanked by AAV2 ITR. After viral preparation, we determined the ability of AAVNPY to produce NPY in cultured AAV-293 cells infected with viral vectors. We validated that hrGFP was expressed in AAVNPY-infected cells by fluorescent microscopy (Fig. 1B) and NPY protein was produced by AAVNPY as determined by Western blot analysis (Fig. 1C).

\section{NPY overexpression in the DMH}

To explore the potential role of DMH NPY in energy balance, we produced a rat model with AAV-mediated NPY overexpression localized to the DMH by injecting AAVNPY (or AAVGFP) bilaterally into the DMH of 10 -week-old male Sprague Dawley rats. We verified that viral vectors successfully infected the cells within and around the compact subregion of the DMH (Fig. $1 D$, hrGFPpositive cells; E, Npy mRNA expression) and that this infection did not occur in other hypothalamic areas (Fig. $1 E$ ). As shown in Figure $1 D$, hrGFP expression was strongly detected in the DMH as early as 2 weeks after viral injection. Consistent with the feature of maintaining gene expression for long periods, determination of mRNA levels by in situ hybridization confirmed that AAVNPY produced a 2.3-fold increase in Npy expression in the DMH relative to control levels at 11 weeks after viral injection. Importantly, NPY expression in the ARC was not affected (Fig. 1E).

\section{NPY overexpression in the DMH alters energy balance}

We examined body weight gain in AAVNPY- and AAVGFPinjected rats. We found that the AAVNPY rats started to gain significantly more weight than the AAVGFP rats at 4 weeks after viral injection such that they gained 14 and $20 \%$ more weight compared with AAVGFP rats at $4(p=0.011)$ and 5 weeks $(p<$ 0.001 ), respectively (Fig. $1 F$ ). The effects of DMH AAVNPY injections were long-lasting. We found that AAVNPY rats had sustained increases in body weight and gained $16 \%$ more than AAVGFP rats over 16 weeks after viral injection $(510 \pm 13 \mathrm{~g}$ in AAVNPY vs $441 \pm 19 \mathrm{~g}$ in AAVGFP; $n=5 ; p=0.017)$. To see whether NPY overexpression in the DMH altered susceptibility to high-fat diet-induced obesity, we switched rats from the regular chow to the high-fat diet 5 weeks after viral injection (Fig. $1 F$ ). Six weeks of access to a high-fat diet resulted in significant increases in weight gain in both AAVNPY and AAVGFP rats $(p<$ 0.001), but the rate of weight gain in the AAVNPY rats was significantly greater $(p<0.001)$ (Fig. $1 F)$. Overall, AAVNPY rats gained 34\% more weight than AAVGFP rats by the end of 6 weeks of access to a high-fat diet (Fig. $1 F$ ).

An analysis of the food intake data revealed that AAVNPY rats ate significantly more regular chow than AAVGFP rats during weeks $4(p=0.016)$ and 5 ( $p=0.011)$ after viral injection (Fig. $1 G)$. The increase in weight gain discussed above coincided with 
A

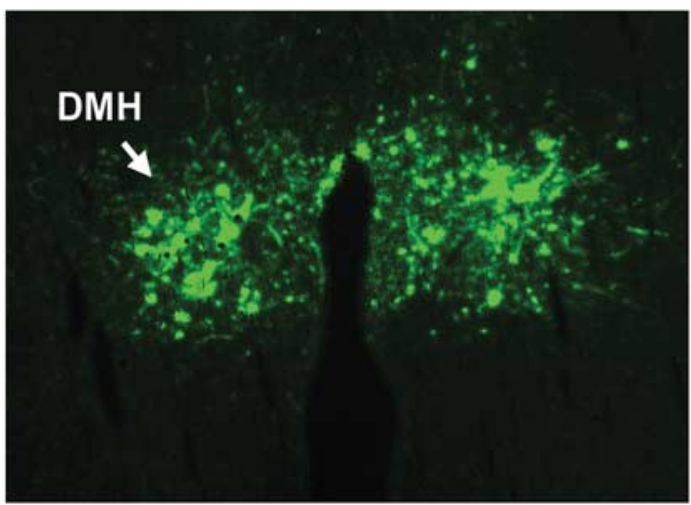

\section{LETO-} AAVshCTL

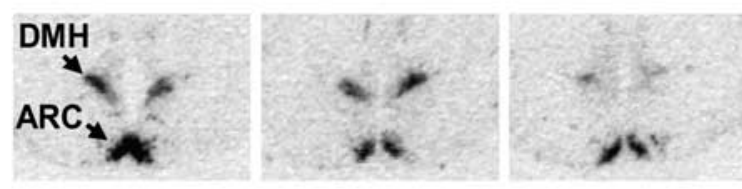

B

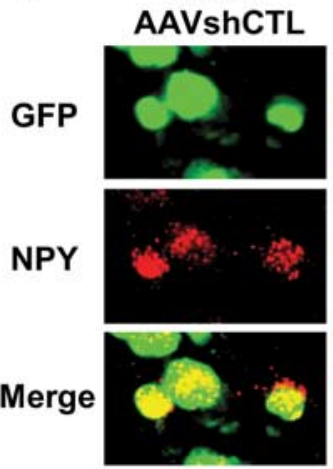

D

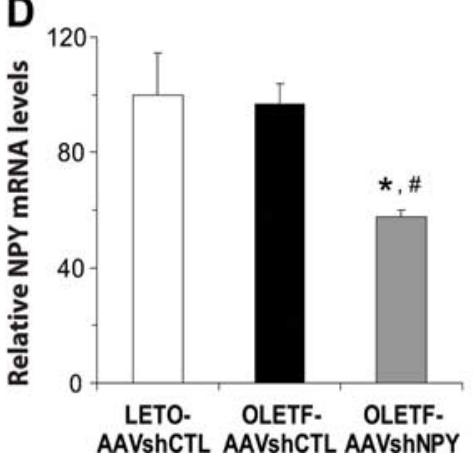

OLETFAAVshCTL
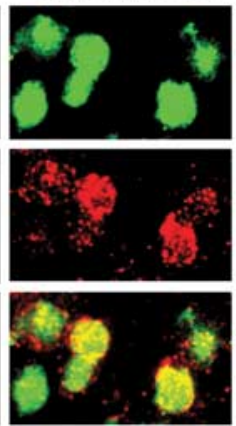

E

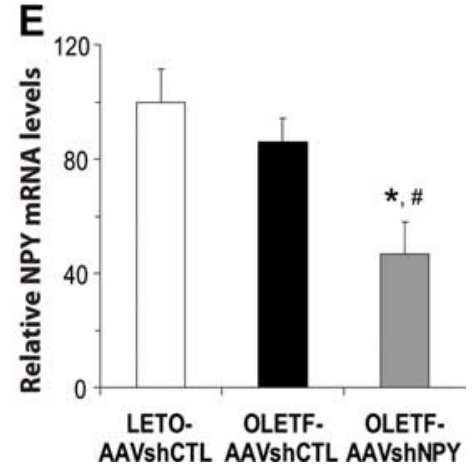

Figure 4. AAV-mediated knockdown of NPY expression in the DMH. $A$, Representative micrograph shows hrGFP expression in the DMH after viral DMH injection as examined under fluorescence microscopy. B, Representative micrograph shows Npy expression (red) in AAVshCTL-infected (hrGFP; green) neurons (orange) in LETO-AAVshCTL and OLETF-AAVshCTL rats, but not in AAVshNPYinfected (green) neurons in OLETF-AAVshNPY rats, as determined by dual fluorescent in situ hybridization for Npy and immunohistochemistry for GFP. LETO-AAVshCTL, Lean LETO rats receiving bilateral DMH injection of AAVshCTL; OLETF-AAVshCTL, OLETF rats receiving bilateral DMH injection of AAVshCTL; OLETF-AAVshNPY, OLETF rats receiving bilateral DMH injection of AAVshNPY. C, ${ }^{35}$ S-labeled in situ hybridization histochemistry shows Npy expression in the compact subregion of the DMH in LETO-AAVshCTL and OLETF-AAVshCTL rats, but less expression in OLETF-AAVshNPY rats. $\boldsymbol{D}, \boldsymbol{E}$, Mean \pm SEM Npy mRNA levels in the DMH of rats at $5(\boldsymbol{D})$ and 20 weeks $(\boldsymbol{E})$ after viral injection. $n=6$ rats per group. ${ }^{*} p<0.05$ compared with LET0-AAVshCTL rats; ${ }^{*} p<0.05$ compared with OLETF-AAVshCTL rats.

this increase in food intake. Access to a high-fat diet resulted in increased food intake in both groups of rats, but NPY overexpression in the $\mathrm{DMH}$ resulted in a significantly greater increase in daily caloric intake during weeks 7, 9, 10, and 11 after viral injection, leading to overall increases in cumulative intake of AVVNPY rats from $9 \%$ on a regular chow diet to $48 \%$ on a high-fat diet relative to a basal level of AAVGFP rats, whereas the cumulative intake of AAVGFP rats increased only by $27 \%$ on a high-fat diet from their basal levels (Fig. 1G).

\section{Knockdown of NPY expression via AAV-mediated RNAi}

We used the technique of RNAi (Fire et al., 1998) to directly determine the function of DMH NPY. We first screened a series of $N p y$-specific shRNAs (Fig. $2 A$, shNPY1-4) for their efficacy in knocking down Npy gene expression in vitro using the pSilencer 1.0-U6 siRNA expression vector. We identified that shNPY2 produced a robust knockdown effect on Npy mRNA expression relative to a control shCTL (Fig. $2 B$ ). We further examined the knockdown effects of shNPY2 in a dose-related manner by cotransfecting the plasmids shNPY2 and pAAVNPY at a range of ratios from 2:1 to 8:1 into AAV-293 cells. Seventy-two hours after transfection, we lysed cells and examined levels of Npy mRNA and protein using real-time RT-PCR and Western blot analysis, respectively. We found that shNPY2 produced a dose-related inhibition of Npy mRNA expression (Fig. 2C) and NPY protein product (Fig. 2D). To determine whether this knockdown effect was gene specific, we examined the effects of shNPY2 on mRNA expression of CCK1 receptors in an in vitro study. We cotrans- fected the plasmid shNPY2 (or shCTL) into AAV 293 cells with the CCK1 receptor expression plasmid at a ratio of 8:1 using Lipofectamine 2000. Seventy-two hours after transfection, total RNA was extracted and CCK1 receptor expression was determined by quantitative real-time RT-PCR. We found that CCK1 receptor mRNA levels did not differ between the shNPY2 and shCTL groups $(100 \pm 9.1$ in shCTL-transfected cells vs $97 \pm 14.8$ in shNPY2-transfected cells; $p>0.05$ ), indicating that the knockdown effect of shNPY2 was gene specific.

We next generated a recombinant vector of AAV-mediated RNAi with shNPY2 (AAVshNPY) for in vivo study. As shown in Figure $3 A$, the vector AAVshNPY contains mouse U6 promoterdriven shNPY (or shCTL for AAVshCTL) and CMV promoterdriven hrGFP marker. Because it has been well known that ARC NPY mediates the feeding response to food deprivation (Spiegelman and Flier, 2001; Schwartz and Porte, 2005), we tested AAVshNPY-mediated RNAi in vivo by injecting AAVshNPY or AAVshCTL bilaterally into the ARC of adult Sprague Dawley rats. We found that ARC injection of AAVshNPY (Fig. $3 B$, hrGFP-positive cells) significantly inhibited Npy mRNA expression in the ARC (Fig. $3 D, E, H$ ) with the result that the feeding response to $24 \mathrm{~h}$ food deprivation was significantly reduced (Fig. $3 C$ ). Moreover, we determined NPY-specific knockdown effects of RNAi. Although NPY and agouti-related protein (AgRP) are colocalized in the ARC neurons (Broberger et al., 1998; Hahn et al., 1998), levels of Agrp mRNA expression in the ARC did not significantly differ between AAVshNPY and AAVshCTL rats (Fig. $3 F-H$ ). Thus, we successfully documented that AAVshNPY 

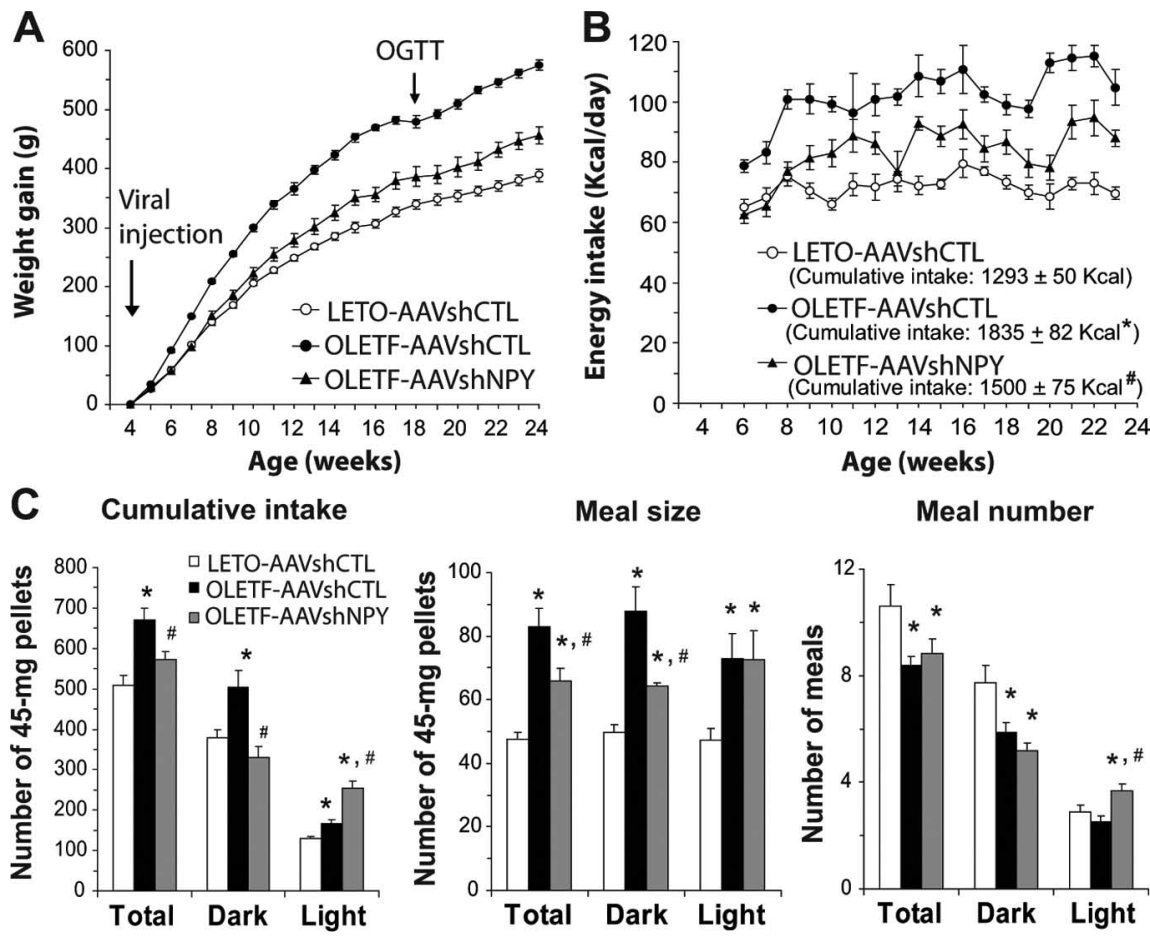

Figure 5. Effects of DMH NPY knockdown on food intake and body weight in OLETF rats. $\boldsymbol{A}$, Mean \pm SEM body weight gain in LETO-AAVshCTL, OLETF-AAVshCTL, and OLETF-AAVshNPY rats. $n=6$ rats per group. OGTT indicates the time when oral glucose tolerance test was conducted. $B$, Mean \pm SEM food intake in the three groups of rats. $n=6$ rats per group. $C$, Patterns of $24 \mathrm{~h}$ food intake in the three groups of rats. Total, Total daily; Dark, the dark period; Light, the light period. Values are means \pm SEM. $n=$ 6 rats per group. ${ }^{*} p<0.05$ compared with LET0-AAVshCTL rats; ${ }^{\#} p<0.05$ compared with OLETF-AAVshCTL rats.
OLETF-AAVshNPY and OLETFAAVshCTL rats, and both groups of rats had similarly reduced ARC Npy mRNA expression compared with LETO rats (Fig. $4 C)$. Such a reduction of ARC NPY expression in OLETF rats is consistent with our previous results and likely attributable to their increased leptin levels (Bi et al., 2001).

\section{Effects of DMH NPY knockdown on body weight and food intake}

As early as 6 weeks of age, OLETFAAVshCTL rats gained significantly more weight than LETO-AAVshCTL rats, but this increase was prevented by knockdown of NPY expression in the DMH (Fig. 5A). As a result, the rate of weight gain did not differ between OLETF-AAVshNPY and LETO-AAVshCTL rats out until 11 weeks of age (Fig. 5A). The effects of AAVshNPY injection were long lasting. At 24 weeks of age, OLETF-AAVshCTL rats gained $48 \%$ more weight than LETO-AAVshCTL rats, whereas the weight gain of OLETFAAVshNPY rats was only $17 \%$ higher than that of LETO-AAVshCTL rats (Fig. 5A).

Knockdown of NPY expression in the DMH also significantly decreased the hyperphagia of OLETF rats. OLETFAAVshCTL rats consumed $42 \%$ more is capable of producing RNAi in vivo to specifically knock down Npy mRNA expression and inhibit NPY function.

\section{Knockdown of NPY expression in the DMH}

We found that OLETF rats have elevated Npy mRNA expression in the $\mathrm{DMH}$ at developmental time points before their obesity and a time when their food was pair-fed to the intake of lean controls and such pair-feeding normalized their body weight (Bi et al., 2001). We have suggested that NPY overexpression in the DMH contributes to the hyperphagia and obesity of OLETF rats (Bi et al., 2001). To further identify the role of DMH NPY in energy balance, we examined the effects of knockdown of DMH NPY expression on hyperphagia and obesity in OLETF rats. After DMH viral injections, we examined hrGFP and NPY expression in the DMH. As expected, viral vectors infected the neurons within the DMH (Fig. 4A, hrGFP-positive neurons), and AAVshNPY injection significantly knocked down DMH Npy mRNA expression (Fig. 4 B, C). Dual labeling of hrGFP and NPY revealed that $N p y$ expression was strongly detected in the DMH neurons that were infected by AAVshCTL in both LETO-AAVshCTL and OLETF-AAVshCTL rats, whereas Npy expression was greatly suppressed in AAVshNPY-infected neurons in OLETFAAVshNPY rats (Fig. 4B). Determination of mRNA expression by in situ hybridization confirmed that $N p y$ was expressed in the compact subregion of the DMH in LETO-AAVshCTL and OLETF-AAVshCTL rats, but $N p y$ expression at this site was greatly suppressed in OLETF-AAVshNPY rats (Fig. 4C). AAVshNPY injection produced a 42 and $45 \%$ suppression of $N p y$ mRNA expression in the DMH of OLETF-AAVshNPY rats relative to OLETF-AAVshCTL rats at 5 (Fig. 4D) and 20 weeks after viral injection (Fig. $4 E$ ), respectively. This knockdown effect was site specific. NPY expression in the ARC did not differ between food than LETO-AAVshCTL rats over the experimental period $(p<0.001)$ (Fig. 5B). This increased intake was significantly reduced by knockdown of DMH NPY expression. OLETFAAVshNPY rats ate significantly less food than did OLETFAAVshCTL rats $(p=0.005)$ (Fig. 5B). Although OLETFAAVshNPY rats consumed $16 \%$ more cumulative food than LETO-AAVshCTL rats, this difference did not reach statistical significance $(p=0.063)$ (Fig. $5 B)$.

\section{Effects of DMH NPY knockdown on feeding behavior}

We analyzed patterns of $24 \mathrm{~h}$ food intake using a feeding monitoring system and found that knockdown of DMH NPY expression produced a nocturnal- and meal size-specific feeding effect. Although OLETF-AAVshCTL rats consumed significantly more food than LETO-AAVshCTL rats during both dark and light periods, the increased intake during the dark period was completely normalized in OLETF-AAVshNPY rats (Fig. 5C). OLETFAAVshNPY rats increased food intake during the light period compared with OLETF-AAVshCTL rats (Fig. 5C), but this increase was not sufficient to compensate for the decrease in food intake during the dark period. Overall, although the daily intake was greatly increased in OLETF-AAVshCTL rats, the total intake of OLETF-AAVshNPY rats was not significantly different from that of LETO-AAVshCTL rats $(p=0.093)$ (Fig. $5 C$ ). Meal pattern analysis revealed that, although meal size was significantly increased in OLETF-AAVshCTL rats compared with LETOAAVshCTL rats overall and during both dark and light periods, knockdown of DMH NPY expression significantly decreased the total increased meal size by specifically decreasing meal size during the dark period (Fig. 5C). Knockdown of DMH NPY expression did not affect total meal number or the number of meals 
during the dark period but did result in increased meal number during the light period (Fig. 5C).

\section{Effects of DMH NPY knockdown on glucose homeostasis}

At 18 weeks of age, OLETF rats develop hyperglycemia and diabetes (Kawano et al., 1992). To determine whether these alterations were affected by knockdown of DMH Npy expression, we performed an oral glucose tolerance test in rats at 18 weeks of age. Consistent with previous results (Kawano et al., 1992), OLETFAAVshCTL rats were hyperglycemic and hyperinsulinemic and became glucose intolerant and insulin insensitive (Fig. $6 A, B)$, indicating that OLETFAAVshCTL rats had altered glucose homeostasis and developed diabetes. Knockdown of DMH NPY expression and the resulting decreases in food intake and body weight resulted in significant ameliorations of these alterations (Fig. 6A,B). Again, these effects were long lasting. At 24 weeks of age, nonfasting glucose levels in OLETF-AAVshCTL rats were much higher than those of LETO-AAVshCTL rats $(205 \pm 24 \mathrm{mg} / \mathrm{dl}$ in OLETFAAVshCTL vs $117 \pm 6 \mathrm{mg} / \mathrm{dl}$ in LETOAAVshCTL rats; $p<0.001$ ), whereas this hyperglycemia was significantly lowered in OLETF-AAVshNPY rats $(137 \pm 7 \mathrm{mg} / \mathrm{dl})$, down to levels similar to those of LETOAAVshCTL rats $(p=0.366)$.

\section{Effects of DMH NPY knockdown on fat mass and plasma levels of leptin and triglyceride}

Increased body fat and plasma leptin levels are features of obesity in OLETF rats (Bi et al., 2001). We next determined the effects of knockdown of DMH NPY expression and the resulting decreases in food intake and body weight on fat mass and plasma leptin levels at killing. We measured the epididymal and subcutaneous white fat as well as the interscapular brown fat and found that knockdown of DMH NPY expression significantly attenuated these increased fat accumulation that characterizes OLETF rats (Fig. 6C). Consistent with changes in body fat mass, plasma leptin levels were significantly elevated in OLETF-AAVshCTL rats, whereas this elevation was significantly reduced in OLETF-AAVshNPY rats (Fig. 6D).

Stafford et al. (2008) have recently reported that central NPY signaling modulates very low-density lipoprotein (VLDL) triglyceride secretion. We examined plasma triglyceride levels in OLETF rats at killing. We found that OLETF-AAVshCTL rats had significantly increased levels of plasma triglycerides (202 \pm $13 \mathrm{mg} / \mathrm{dl}$ ) compared with LETO-AAVshCTL rats $(94 \pm 5 \mathrm{mg} / \mathrm{dl}$; $p<0.001)$. This elevation was significantly lowered in OLETFAAVshNPY rats $(133 \pm 17 \mathrm{mg} / \mathrm{dl} ; p=0.014$ compared with OLETF-AAVshCTL rats), reaching normal levels as seen in LETO-AAVshCTL rats $(p=0.144)$.
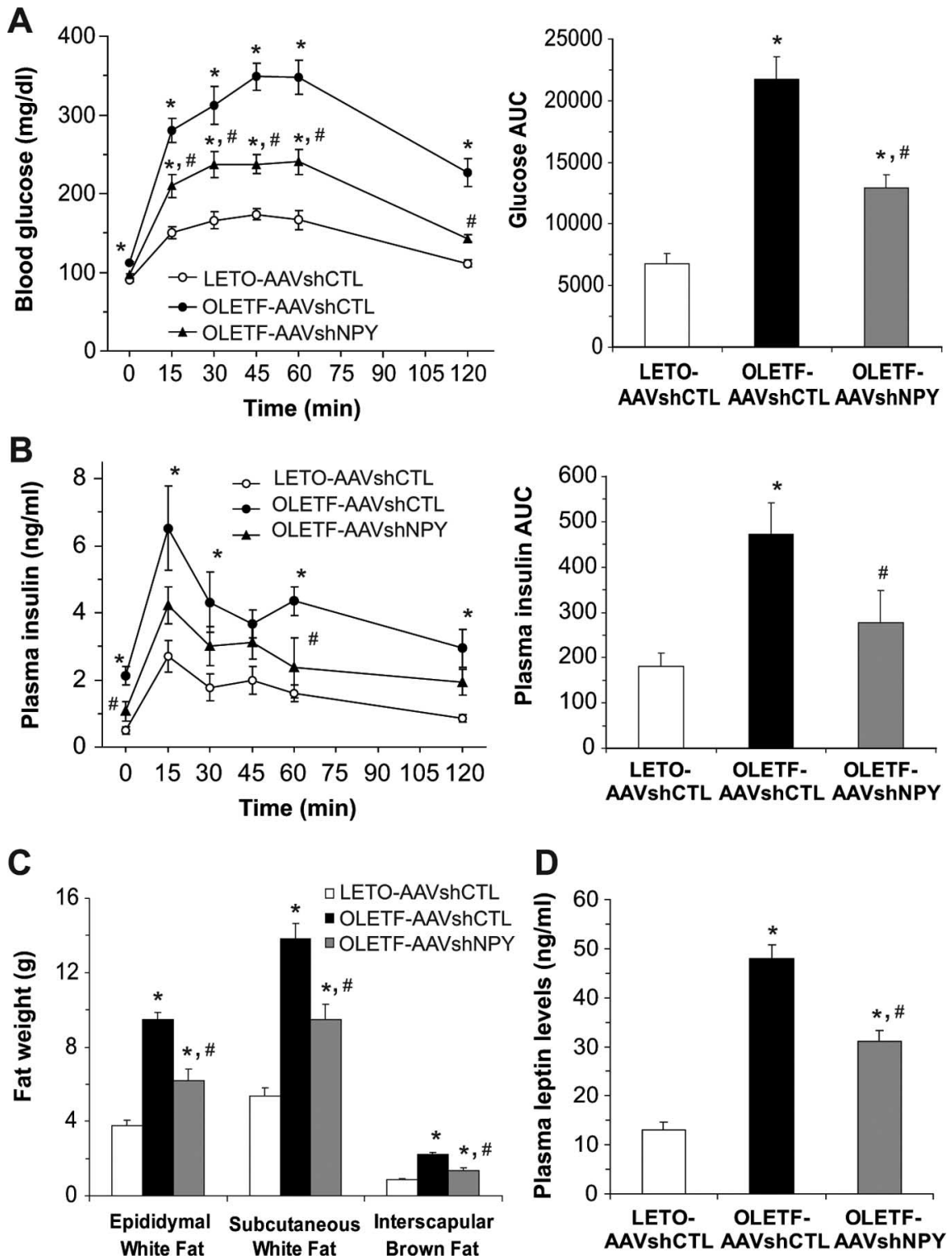

Figure 6. Effects of DMH NPY knockdown on levels of blood glucose and plasma insulin and leptin as well as fat mass in OLETF rats. $\boldsymbol{A}$, Blood glucose response to oral glucose administration. $\boldsymbol{B}$, Plasma insulin response to oral glucose administration. $\boldsymbol{C}$, Fat weights at three different sites in the three groups of rats. $\boldsymbol{D}$, Plasma leptin levels in the three groups of rats. Values are means \pm SEM. $n=6$ rats per group. ${ }^{*} p<0.05$ compared with LETO-AAVshCTL rats; ${ }^{\#} p<0.05$ compared with OLETF-AAVshCTL rats.

\section{DMH NPY modulates within-meal satiation signaling}

The finding that knockdown of NPY expression in the DMH has a specific effect on meal size (Fig. 5C) suggests an interaction of DMH NPY projections with systems that mediate within-meal feedback signaling. Because the brainstem DVC is the site of reception of gastrointestinal satiation signals (such as CCK) that control the size of individual meals (Moran, 2004), we next determined whether DMH NPY modulates within-meal satiation signaling through actions at brainstem sites. We first examined whether NPY neurons in the DMH project to the brainstem by injecting AAVshNPY into the DMH and examining NPY fiber immunostaining with anti-NPY antibody in the brainstem. We found that unilateral injection of AAVshNPY strongly infected neurons within the injected DMH (Fig. 7A, hrGFP-positive neurons) and suppressed Npy mRNA expression in the ipsilateral $\mathrm{DMH}$ (Fig. 7B). Again, this knockdown effect was confined within the site of DMH injection without affecting Npy mRNA 


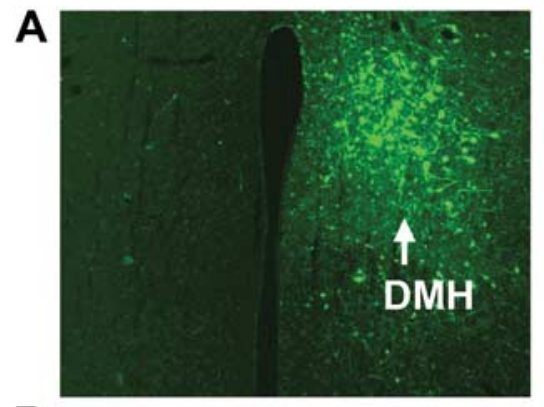

B
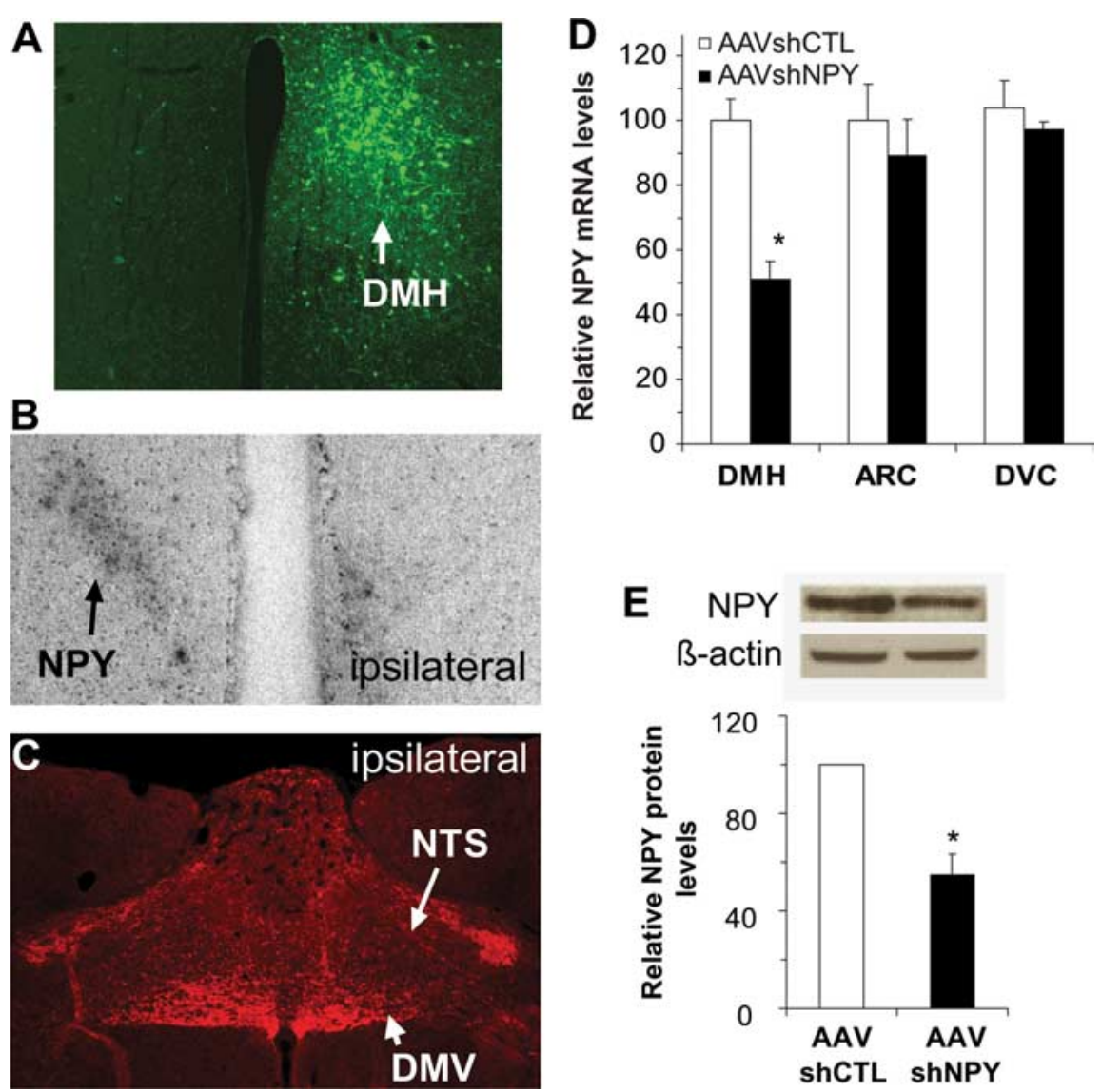

Figure 7. Knockdown of DMH NPY expression alters NPY signaling to the brainstem. $\boldsymbol{A}-\boldsymbol{C}$, Unilateral injection of AAVshNPY into the DMH (hrGFP-positive neurons) ( $\boldsymbol{A}$ ) suppressed ipsilateral Npy expression (B) and resulted in decreased NPY fiber (red) staining in the ipsilateral site of the NTS and the DMV (C).D, Npy gene expression was specifically suppressed in the DMH but not in the ARC and the DVC in rats receiving DMH AAVshNPY injections (AAVshNPY) relative to control rats receiving AAVshCTL injections (AAVshCTL) as determined by quantitative real-time RT-PCR. $n=5$ rats per group. ${ }^{*} p<0.05$ compared with AAVshCTL rats. $\boldsymbol{E}$, NPY protein levels were decreased in the DVC of AAVshNPY rats compared with AAVshCTL rats $\left(n=5\right.$ rats per group; ${ }^{*} p<$ 0.05 ) as determined by Western blot.

expression in either the ARC or DVC as determined by real time RT-PCR (Fig. 7D). Immunohistochemistry revealed that the unilateral DMH injection of AAVshNPY significantly decreased NPY fiber (red) staining in the ipsilateral regions of the NTS and the dorsal motor nucleus of vagus (DMV), particularly in the medial and intermediate parts of the NTS and the lateral part of the DMV, compared with the contralateral areas (Fig. 7C). Overall, AAVshNPY injection resulted in a $45 \%$ reduction in NPY protein levels in the DVC as determined by Western blot analysis (Fig. 7E). Thus, NPY neurons in the DMH project to the NTS/DMV, and suppression of Npy mRNA expression in the DMH reduces NPY protein levels at these projection sites, raising the possibility that alterations in feeding in response to changes in DMH NPY expression are mediated through alterations in NPY signaling at this brainstem site. To test this possibility, we examined the feeding response to peripheral administration of CCK in intact rats receiving bilateral DMH injections of AAVshNPY. As we had seen in OLETF rats, knockdown of NPY expression in the $\mathrm{DMH}$ of intact rats significantly decreased meal size during the dark period (from $65 \pm 5.9$ to $49 \pm 3.745 \mathrm{mg}$ pellets; $n=$ 6 ; $p=0.044)$. We tested the feeding inhibitory effects of peripheral CCK administration in AAVshNPY rats and AAVshCTL rats of comparable body weight $(526 \pm 11 \mathrm{~g}$ in AAVshNPY rats and $527 \pm 18 \mathrm{~g}$ in AAVshCTL rats; $p>0.05)$. We found that peripheral administration of CCK produced a greater feeding inhibition in AAVshNPY rats than in AAVshCTL rats (Fig. $8 A$ ). Consistent with these feeding data, c-Fos-like immunohistochemistry revealed that peripheral CCK administration produced significantly more $\mathrm{c}$-Fos activation in the NTS and the AP of AAVshNPY rats compared with AAVshCTL rats (Fig. $8 B, C$ ).

\section{Discussion}

We examined the functions of DMH NPY in the regulation of energy balance by using AAV-mediated alterations in $\mathrm{DMH}$ NPY expression. We found that AAVmediated NPY overexpression in the $\mathrm{DMH}$ of lean rats increased food intake and body weight, and exacerbated high-fat diet-induced obesity. Knockdown of NPY expression in the DMH via AAV-mediated RNAi ameliorated the hyperphagia, obesity, and diabetes of OLETF rats. DMH NPY knockdown produced a nocturnaland meal size-specific feeding effect. Moreover, we found that DMH NPY knockdown in intact rats reduced NPY signaling in the NTS/DMV to affect within-meal satiation. DMH NPY knockdown increased the feeding inhibitory and NTS c-Fos responses to peripheral administration of CCK. Together, these results indicate that DMH NPY plays an important role in modulating food intake and energy balance.

We first generated a vector of AAVmediated NPY expression to investigate the consequences of NPY overexpression in the DMH of intact rats. We found that AAV-mediated NPY overexpression in the DMH resulted in increased food intake and body weight. Consistent with the proposed role for DMH NPY overexpression in exaggerating the hyperphagia and obesity in OLETF rats on a high-fat diet (Bi et al., 2007), AAV-mediated NPY overexpression in the DMH resulted in an exacerbation of high-fat diet-induced hyperphagia and obesity. Although this experiment did not examine the aspect of energy expenditure, it appears that the increases in food intake were sufficient to account for the increased body weight changes in AAVNPY rats on both chow and high-fat diets. Their increased food intake would predict 31 and 87 g greater weight changes on chow and high fat diet, respectively, amounts not significantly different from the actual increased weight gains. Nevertheless, because neurons in the DMH have been shown to play a role in thermoregulation (Dimicco and Zaretsky, 2007), direct effects of alterations in DMH NPY expression on energy expenditure are worth investigating.

We next examined the actions of DMH NPY in energy balance by bilaterally injecting AAVshNPY into the DMH of OLETF rats and examining whether DMH NPY knockdown prevents their hyperphagia, obesity, and diabetes. We found that AAVmediated knockdown of DMH NPY expression significantly decreased food intake, body weight, and body fat of OLETF rats. The effects on food intake were specific to the documented in- 
creases in meal size in this model (Moran et al., 1998). Although OLETFAAVshNPY rats increased weight gain at later times as likely some form of compensation, this increase was small so that they maintained significantly lower body weight. Moreover, DMH NPY knockdown ameliorated the hyperglycemia and hyperleptinemia and restored insulin sensitivity in OLETF rats. Because caloric restriction lowers body weight as well as prevents hyperglycemia, hyperleptinemia, and hyperinsulinemia in OLETF rats (Okauchi et al., 1995; Bi et al., 2001), these ameliorations resulting from DMH NPY knockdown are likely a consequence of their reduced body weight. Furthermore, although OLETF rats developed hypertriglycerides, DMH NPY knockdown reduced this elevation, implying one possibility that DMH NPY might be involved in VLDL triglyceride secretion (Stafford et al., 2008). Nevertheless, our results provide strong evidence demonstrating that DMH NPY overexpression plays a major role in the hyperphagia, obesity, and diabetes of OLETF rats, and also identify the physiological functions of DMH NPY in the regulation of energy balance.

NPY expression is differentially regulated in the ARC and the DMH. Whereas ARC Npy mRNA expression is increased in response to both acute food deprivation and chronic food restriction, DMH Npy expression is only increased in response to chronic food restriction (Bi et al., 2003). Although obese rodents have increased Npy expression in the DMH, their ARC Npy expression is unchanged or even decreased (Kesterson et al., 1997; Guan et al., 1998a,b; Tritos et al., 1998; Bi et al., 2001). The control of NPY signaling also differs between the ARC and the DMH. Whereas ARC NPY signaling is under the control of leptin (Schwartz and Porte, 2005), a hormone that is produced in adipocytes and acts as a feedback signal to the hypothalamus regarding body energy stores (Friedman and Halaas, 1998), DMH NPY signaling appears to be independent of leptin. DHM NPY neurons do not express leptin receptors (Bi et al., 2003) but do contain CCK1 receptors (Bi et al., 2004). DMH NPY has been suggested to mediate the feeding actions of central CCK (Chen et al., 2007) and those of other peptides including melanocortins (Chen et al., 2004), galanin-like peptide (Kuramochi et al., 2006), and unknown molecules (Bi et al., 2005). Although ARC NPY mediates the feeding actions of ghrelin (Nakazato et al., 2001), a relationship between ghrelin and DMH NPY signaling has yet to be determined. The downstream consequences of DMH NPY signaling are also different from that
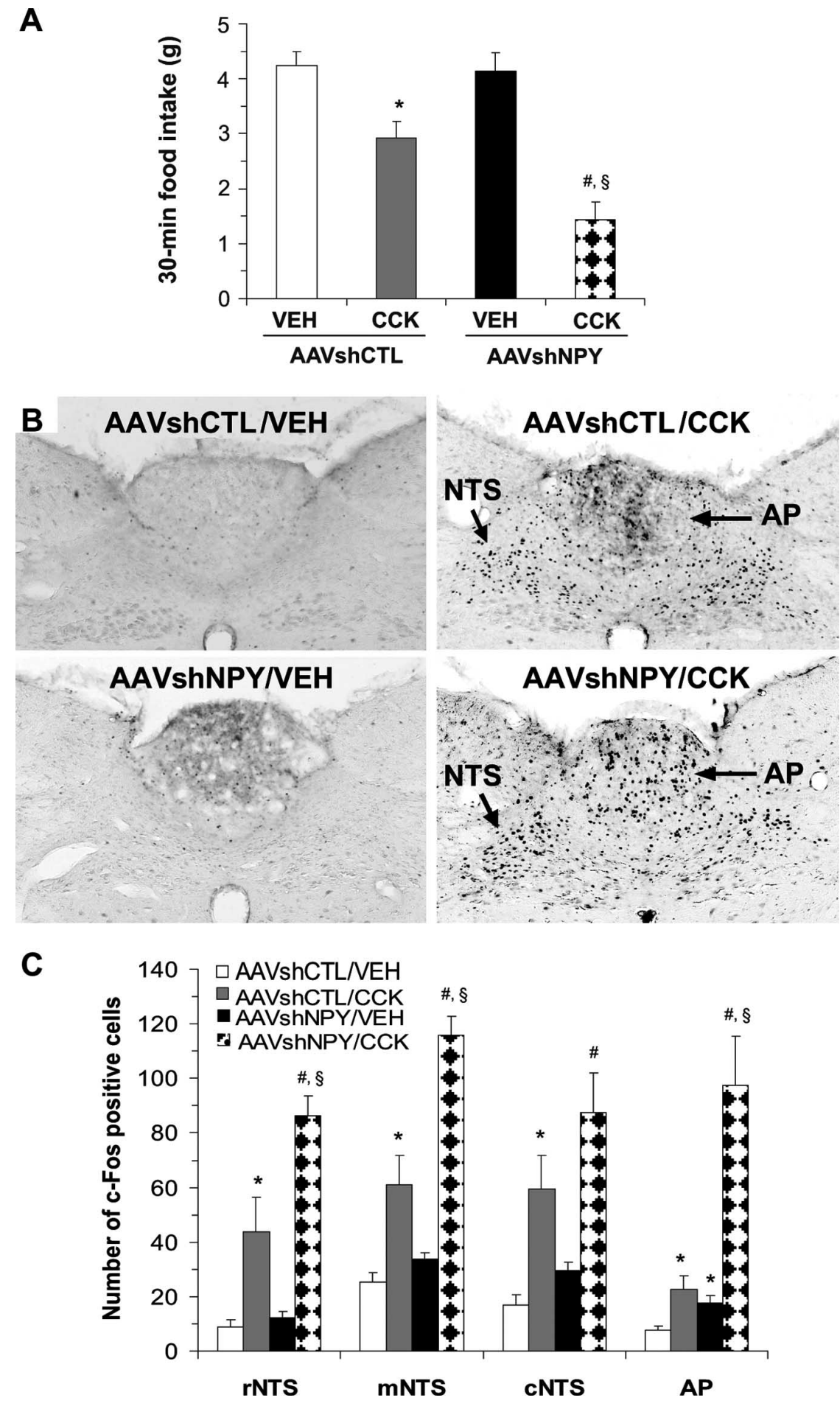

Figure 8. DMH NPY modulates satiation actions of peripheral CCK. A, Knockdown of DMH NPY expression enhanced CCK-induced feeding inhibition. VEH, Vehicle-treated rats; CCK, CCK-treated rats. $n=10$ rats per group. ${ }^{*} p<0.05$ compared with AAVshCTL/VEH, ${ }^{\#} p<0.05$ compared with AAVshNPY/NEH, and ${ }^{\S} p<0.05$ compared with AAVshCTL/CCK. B, Representative micrograph shows c-Fosimmunoreactive response to peripheral administration of CCK in the NTS and the AP. AAVshCTL/NEH, Vehicle-treated AAVshCTL rats; AAVshCTL/CCK, CCK-treated AAVshCTL rats; AAVshNPY/NEH, vehicle-treated AAVshNPY rats; AAVshNPY/CCK, CCK-treated AAVshNPY rats. C, Mean \pm SEM c-Fos-positive neurons produced by peripheral administration of CCK. rNTS, Rostral NTS (-13.44); mNTS, medial NTS $(-13.8)$; CNTS, caudal NTS $(-14.28)$; also shown is AP $(-13.8) . n=5$ rats per group. ${ }^{*} p<0.05$ compared with AAVshCTL/NEH, ${ }^{\#} p<$ 0.05 compared with AAVshNPY/VEH, and ${ }^{\S} p<0.05$ compared with AAVshCTL/CCK.

of ARC NPY. ARC NPY neurons primarily project to the PVN and $\mathrm{LH}$ and innervate local neurons to affect energy balance (Elmquist et al., 1999). Bugarith et al. (2005) reported that lesions of basomedial hypothalamic NPY receptor-expressing neurons 
(including ARC NPY neurons) by NPY conjugated to saporin affected daytime but not nighttime food intake. Such lesions did not alter the feeding response to peripheral administration of CCK (Bugarith et al., 2005). In contrast, the current studies revealed that AAV-mediated knockdown of DMH NPY expression produced a nocturnal-specific feeding effect. This knockdown resulted in decreased NPY signaling to the NTS/DMV, leading to decreased meal size and increased feeding inhibitory response to peripheral administration of CCK. Thus, these data identified a physiological function of DMH NPY in feeding control [i.e., DMH NPY normally affects food intake through specifically affecting meal size by modulating within-meal satiation signal (such as CCK) in the brainstem]. Such data also provide a basis for the interpretation of the findings that DMH lesions that damage DHM NPY neurons result in hypophagia characterized by a specific reduction in meal size (Bellinger et al., 1986).

A role for the $\mathrm{DMH}$ in food-entrainable circadian behavior has been suggested from previous studies. Although there is some controversy over the effect of DMH lesions on food anticipatory activity (Gooley et al., 2006; Landry et al., 2006), Mieda et al. (2006) have demonstrated a robust oscillation of Per1 and Per2 expression in the compact subregion of the $\mathrm{DMH}$ only under restricted feeding. Combined with our previous findings that food restriction elevates $N p y$ expression in this area (Bi et al., 2003), data from the current findings of the nocturnal feeding effects of DMH NPY imply that DMH NPY may also serve as an important regulator of circadian feeding. Such actions merit additional investigation.

Consistent with the reported actions of RNAi, our in vitro and in vivo experiments demonstrated that shNPY produced a robust and selective suppression of NPY expression. Because the shRNA could produce off-target effects, we have attempted to control for such possibilities in multiple ways. We have used scrambled shRNA for our control injections so that effects of the targeted manipulations can be differentiated from those of viral infections. In a number of the in vitro and in vivo manipulations, we have measured the expression of other genes and shown that they were unaffected. For instance, in vitro shNPY produced a doserelated suppression on $N p y$ mRNA expression and protein levels, but did not affect CCK1 receptor gene expression compared with shCTL. Bilateral injection of AAVshNPY into the ARC of adult rats significantly decreased ARC Npy gene expression without affecting Agrp expression. Moreover, we have shown that the expression of ARC NPY is not affected by knockdown of DMH NPY, documenting the site-specific nature of the manipulation. Despite these controls, there is always the possibility that some aspects of the results are not directly attributable to changes in DMH NPY expression.

A final issue is how the present results should be interpreted in the context of multiple experiments in mice aimed at targeting NPY [either knock-out (Erickson et al., 1996) or transcriptional alterations through doxycycline-regulated system (Ste Marie et al., 2005)] that have failed to demonstrate significant effects on food intake or body weight. There are multiple possibilities. One possibility is a species difference. In support of this view, we have previously shown that Npy gene is expressed in the DMH of rats, but its expression is undetectable in mice (Bi et al., 2004). Another possibility is that the mode of alteration in NPY expression makes a difference. Viral-mediated NPY alterations appear to produce long-lasting effects. Both AAV-mediated expression of antisense NPY in the ARC (Gardiner et al., 2005) and AAVmediated ectopic overexpression of NPY in the LH (Tiesjema et al., 2007) altered body weight gain over $50 \mathrm{~d}$. Such data are con- sistent with our results demonstrating AAV-mediated alterations in DMH NPY expression and the resulting changes in food intake and body weight that last for up to 16 weeks in NPY overexpression rats and 20 weeks in NPY knockdown rats. Thus, our present results not only demonstrate the role of DMH NPY in modulating food intake and energy balance in rats, but also provide additional evidence showing the utility of AAV-mediated gene modulation for studying the site-specific gene functions.

\section{References}

Bellinger LL, Mendel VE, Bernardis LL, Castonguay TW (1986) Meal patterns of rats with dorsomedial hypothalamic nuclei lesions or sham operations. Physiol Behav 36:693-698.

Bi S, Ladenheim EE, Schwartz GJ, Moran TH (2001) A role for NPY overexpression in the dorsomedial hypothalamus in hyperphagia and obesity of OLETF rats. Am J Physiol Regul Integr Comp Physiol 281:R254-R260.

Bi S, Robinson BM, Moran TH (2003) Acute food deprivation and chronic food restriction differentially affect hypothalamic NPY mRNA expression. Am J Physiol Regul Integr Comp Physiol 285:R1030-R1036.

Bi S, Scott KA, Kopin AS, Moran TH (2004) Differential roles for cholecystokinin a receptors in energy balance in rats and mice. Endocrinology 145:3873-3880.

Bi S, Scott KA, Hyun J, Ladenheim EE, Moran TH (2005) Running wheel activity prevents hyperphagia and obesity in Otsuka Long-Evans Tokushima Fatty rats: role of hypothalamic signaling. Endocrinology 146:1676-1685.

Bi S, Chen J, Behles RR, Hyun J, Kopin AS, Moran TH (2007) Differential body weight and feeding responses to high-fat diets in rats and mice lacking cholecystokinin 1 receptors. Am J Physiol Regul Integr Comp Physiol 293:R55-R63.

Broberger C, De Lecea L, Sutcliffe JG, Hökfelt T (1998) Hypocretin/orexinand melanin-concentrating hormone-expressing cells form distinct populations in the rodent lateral hypothalamus: relationship to the neuropeptide $\mathrm{Y}$ and agouti gene-related protein systems. J Comp Neurol 402:460-474.

Bugarith K, Dinh TT, Li AJ, Speth RC, Ritter S (2005) Basomedial hypothalamic injections of neuropeptide $\mathrm{Y}$ conjugated to saporin selectively disrupt hypothalamic controls of food intake. Endocrinology 146:1179-1191.

Chen J, Scott KA, Zhao Z, Moran TH, Bi S (2008) Characterization of the feeding inhibition and neural activation produced by dorsomedial hypothalamic cholecystokinin administration. Neuroscience 152:178-188.

Chen P, Williams SM, Grove KL, Smith MS (2004) Melanocortin 4 receptor-mediated hyperphagia and activation of neuropeptide $\mathrm{Y}$ expression in the dorsomedial hypothalamus during lactation. J Neurosci 24:5091-5100.

Chronwall BM, DiMaggio DA, Massari VJ, Pickel VM, Ruggiero DA, O'Donohue TL (1985) The anatomy of neuropeptide-Y-containing neurons in rat brain. Neuroscience 15:1159-1181.

Clark JT, Kalra PS, Crowley WR, Kalra SP (1984) Neuropeptide Y and human pancreatic polypeptide stimulate feeding behavior in rats. Endocrinology 115:427-429.

Dimicco JA, Zaretsky DV (2007) The dorsomedial hypothalamus: a new player in thermoregulation. Am J Physiol Regul Integr Comp Physiol 292:R47-R63.

Elmquist JK, Elias CF, Saper CB (1999) From lesions to leptin: hypothalamic control of food intake and body weight. Neuron 22:221-232.

Erickson JC, Clegg KE, Palmiter RD (1996) Sensitivity to leptin and susceptibility to seizures of mice lacking neuropeptide Y. Nature 381:415-421.

Fire A, Xu S, Montgomery MK, Kostas SA, Driver SE, Mello CC (1998) Potent and specific genetic interference by double-stranded RNA in Caenorhabditis elegans. Nature 391:806-811.

Friedman JM, Halaas JL (1998) Leptin and the regulation of body weight in mammals. Nature 395:763-770.

Gardiner JV, Kong WM, Ward H, Murphy KG, Dhillo WS, Bloom SR (2005) AAV mediated expression of anti-sense neuropeptide Y cRNA in the arcuate nucleus of rats results in decreased weight gain and food intake. Biochem Biophys Res Commun 327:1088-1093.

Gooley JJ, Schomer A, Saper CB (2006) The dorsomedial hypothalamic nucleus is critical for the expression of food-entrainable circadian rhythms. Nat Neurosci 9:398-407. 
Gray TS, Morley JE (1986) Neuropeptide Y: anatomical distribution and possible function in mammalian nervous system. Life Sci 38:389-401.

Guan XM, Yu H, Van der Ploeg LH (1998a) Evidence of altered hypothalamic pro-opiomelanocortin/ neuropeptide Y mRNA expression in tubby mice. Brain Res Mol Brain Res 59:273-279.

Guan XM, Yu H, Trumbauer M, Frazier E, Van der Ploeg LH, Chen H (1998b) Induction of neuropeptide Y expression in dorsomedial hypothalamus of diet-induced obese mice. Neuroreport 9:3415-3419.

Hahn TM, Breininger JF, Baskin DG, Schwartz MW (1998) Coexpression of Agrp and NPY in fasting-activated hypothalamic neurons. Nat Neurosci 1:271-272.

Kawaguchi M, Scott KA, Moran TH, Bi S (2005) Dorsomedial hypothalamic corticotropin-releasing factor mediation of exercise-induced anorexia. Am J Physiol Regul Integr Comp Physiol 288:R1800-R1805.

Kawano K, Hirashima T, Mori S, Saitoh Y, Kurosumi M, Natori T (1992) Spontaneous long-term hyperglycemic rat with diabetic complications. Otsuka Long-Evans Tokushima Fatty (OLETF) strain. Diabetes 41:1422-1428.

Kesterson RA, Huszar D, Lynch CA, Simerly RB, Cone RD (1997) Induction of neuropeptide $\mathrm{Y}$ gene expression in the dorsal medial hypothalamic nucleus in two models of the agouti obesity syndrome. Mol Endocrinol 11:630-637.

Kuramochi M, Onaka T, Kohno D, Kato S, Yada T (2006) Galanin-like peptide stimulates food intake via activation of neuropeptide $\mathrm{Y}$ neurons in the hypothalamic dorsomedial nucleus of the rat. Endocrinology 147:1744-1752.

Landry GJ, Simon MM, Webb IC, Mistlberger RE (2006) Persistence of a behavioral food-anticipatory circadian rhythm following dorsomedial hypothalamic ablation in rats. Am J Physiol Regul Integr Comp Physiol 290:R1527-R1534.

Levine AS, Morley JE (1984) Neuropeptide Y: a potent inducer of consummatory behavior in rats. Peptides 5:1025-1029.

Mieda M, Williams SC, Richardson JA, Tanaka K, Yanagisawa M (2006) The dorsomedial hypothalamic nucleus as a putative food-entrainable circadian pacemaker. Proc Natl Acad Sci U S A 103:12150-12155.

Moran TH (2004) Gut peptides in the control of food intake: 30 years of ideas. Physiol Behav 82:175-180.

Moran TH, Katz LF, Plata-Salaman CR, Schwartz GJ (1998) Disordered food intake and obesity in rats lacking cholecystokinin A receptors. Am J Physiol Regul Integr Comp Physiol 274:R618-R625.

Nakazato M, Murakami N, Date Y, Kojima M, Matsuo H, Kangawa K, Matsukura S (2001) A role for ghrelin in the central regulation of feeding. Nature 409:194-198.

Okada T, Nomoto T, Shimazaki K, Lijun W, Lu Y, Matsushita T, Mizukami H, Urabe M, Hanazono Y, Kume A, Muramatsu S, Nakano I, Ozawa K
(2002) Adeno-associated virus vectors for gene transfer to the brain. Methods 28:237-247.

Okauchi N, Mizuno A, Yoshimoto S, Zhu M, Sano T, Shima K (1995) Is caloric restriction effective in preventing diabetes mellitus in the Otsuka Long Evans Tokushima Fatty rat, a model of spontaneous non-insulindependent diabetes mellitus? Diabetes Res Clin Pract 27:97-106.

Passini MA, Watson DJ, Wolfe JH (2004) Gene delivery to the mouse brain with adeno-associated virus. Methods Mol Biol 246:225-236.

Paxinos G, Watson C (2005) The rat brain in stereotaxic coordinates, Ed 5. San Diego: Elsevier Academic.

Schwartz MW, Porte D Jr (2005) Diabetes, obesity, and the brain. Science 307:375-379.

Smith MS (1993) Lactation alters neuropeptide-Y and proopiomelanocortin gene expression in the arcuate nucleus of the rat. Endocrinology 133:1258-1265.

Spiegelman BM, Flier JS (2001) Obesity and the regulation of energy balance. Cell 104:531-543.

Stafford JM, Yu F, Printz R, Hasty AH, Swift LL, Niswender KD (2008) Central nervous system neuropeptide Y signaling modulates VLDL triglyceride secretion. Diabetes 57:1482-1490.

Stanley BG, Leibowitz SF (1984) Neuropeptide Y: stimulation of feeding and drinking by injection into the paraventricular nucleus. Life Sci 35:2635-2642.

Stanley BG, Kyrkouli SE, Lampert S, Leibowitz SF (1986) Neuropeptide Y chronically injected into the hypothalamus: a powerful neurochemical inducer of hyperphagia and obesity. Peptides 7:1189-1192.

Ste Marie L, Luquet S, Cole TB, Palmiter RD (2005) Modulation of neuropeptide $\mathrm{Y}$ expression in adult mice does not affect feeding. Proc Natl Acad Sci U S A 102:18632-18637.

Tiesjema B, Adan RA, Luijendijk MC, Kalsbeek A, la Fleur SE (2007) Differential effects of recombinant adeno-associated virus-mediated neuropeptide $\mathrm{Y}$ overexpression in the hypothalamic paraventricular nucleus and lateral hypothalamus on feeding behavior. J Neurosci 27:14139-14146.

Tritos NA, Elmquist JK, Mastaitis JW, Flier JS, Maratos-Flier E (1998) Characterization of expression of hypothalamic appetite-regulating peptides in obese hyperleptinemic brown adipose tissue-deficient (uncoupling protein-promoter-driven diphtheria toxin A) mice. Endocrinology 139:4634-4641.

White JD, Kershaw M (1990) Increased hypothalamic neuropeptide Y expression following food deprivation. Mol Cell Neurosci 1:41-48.

Zarjevski N, Cusin I, Vettor R, Rohner-Jeanrenaud F, Jeanrenaud B (1993) Chronic intracerebroventricular neuropeptide-Y administration to normal rats mimics hormonal and metabolic changes of obesity. Endocrinology 133:1753-1758. 